\title{
The Variation of Seasonal Diseases in Family Medicine Depends on Infectious Diseases and these are Mainly Respiratory Diseases
}

Jose Luis Turabian*

Health Center Santa Maria de Benquerencia Toledo, Spain

“Corresponding author: Jose Luis Turabian, Health Center Santa Maria de Benquerencia Toledo, Spain, Tel: 34925154508; E-mail: jturabianf@hotmail.com

Received date: May 03, 2017; Accepted date: May 10, 2017; Published date: May 15, 2017

Copyright: ( 2017 Turabian JL. This is an openaccess article distributed under the terms of the Creative Commons Attribution License, which permits unrestricted use, distribution, and reproduction in any medium, provided the original author and source are credited.

\begin{abstract}
Family medicine is a major source of information about health problems and their variation. For most illnesses the general practitioner is the first point of contact in the health care system and he looks after a population whose age and sex composition is known. He is therefore in an ideal position to conduct inquiries about seasonal variations of diseases. There are diseases where possible patterns of seasonal variation have been established: psychiatric disorders, allergies, heart disease, etc. It has long been accepted that morbidity patterns in general practice vary seasonally, which mainly depends on the acute pathology of infectious origin. In addition, it can be affirmed that respiratory infections represent the most important percentage of infections. So, seasonal variability of diseases in family medicine can be attributed to the variability of respiratory infections. Infectious disease dynamics offer a wide variety of intriguing and unexplained phenomena. There is a gap in how diverse studies encompassing immunology, mathematics, epidemiology, and virology combine to form a complete picture of seasonality. This may be due to the daunting complexity of seasonality itself, which is likely to reflect the actions of a vast multitude of variables. An understanding of what drives seasonal trends may allow: 1) better understanding of transmission dynamics, leading to better methods of prevention, health education, triage, diagnosis and management; 2) generate causal and risk factor hypotheses; 3) awareness of risks and surveillance systems; 4) monitoring the effects of intervention studies such as immunization programs; 5) identifying the specific environmental and socioeconomic factors underlying seasonal transmission; 6) better Interpretation of prevalence or incidence studies; And 7) redistribution of resources for the care of the demand in family medicine and health care system.
\end{abstract}

Keywords: Seasons; Communicable diseases; Respiratory tract infections; Family practice; Morbidity; Health services needs and demand

\section{Introduction}

\section{Family medicine is a major source of information about community health problems}

Primary care is a major source of information on health problems and their variation, which is of great importance in the evaluation of the health of the population, determination of health policies, and measurement of workloads of health professionals, identification of Public Health interventions and resource allocation decisions, and curricular contents of pre and postgraduate physicians and nurses. However, there is a lack of data on the variation trends of the vast majority of common diseases treated in general practice, comparing series collected with invariable methods in a sufficiently long time [1].

For most illnesses, in many health systems, the general practitioner is the first point of contact in the health care system and he looks after a population whose age and sex composition is known. The family doctor is therefore in an ideal position to conduct such inquiries about seasonal variations of diseases. At this health care level, In relation to morbidity studies, we can use the term "minimum frequency" or "minimum incidence" to refer to the incidence reported by the general practitioner and which refers only for those patients who consult him.

\section{The Importance of Seasonality}

Knowledge of seasonal variations and time trends in disease incidence are important to the prediction of epidemics of disease and the consequent potential for better diagnosis and management. They are also important for monitoring the effects of intervention studies such as immunization programmes $[2,3]$.

Why is a focus on the seasonality of infectious diseases and its variation so important? Isn't it more important for us to instead understand the effects of long-term climate change on human health? At first sight, understanding seasonal patterns seems disconnected from understanding the impact of long-term climate change. However, seasonal patterns are one major pathway for the subtle but potentially drastic effects of climate change on disease dynamics. Long-term climate change affects seasonal patterns through the lengthening of the transmission season and the crossing of environmental and demographic thresholds that underlie seasonal outbreaks. Thus, identifying the specific environmental factors underlying seasonal transmission is a critical step towards predicting and understanding how long-term environmental trends in mean climate and their variability will impact human health [3].

\section{Seasonal variations}

The organism in the course of daily life is subjected to continuous metabolic variations in response to external stimuli. These variations tend to be organized cyclically or seasonally, and condition different responses depending on the triggering cause. In a large number of 
Page 2 of 6

health problems have been found a temporary or seasonal pattern of their presentation.

In epidemiology, the study of variations in morbidity includes the study of time series: 1) seasonal variations (those occurring regularly at certain times of the year), and 2) cyclical ones (those manifested over periods of several years). Knowledge of these variations can be related to their associated causes or factors, such as agent ecology, climate and atmospheric phenomena, human activities, human concentration and dispersion, exposure to different agents, etc. This knowledge of the variation or chronological-seasonal evolution of the morbidity allows to control or to manage its frequency, and to establish previsions and interventions. In order to detect seasonal variation, time intervals need to be measured in small units, such as days, weeks, months, or quarters [4].

It is considered that any biomedical variable has a seasonal behaviour, or shows seasonality when its presentation in the different times of the year defined as seasons (astronomical or climatological) is not statistically uniform. In the complex problem of seasonal pathology three groups of seasonal phenomena have been distinguished: 1) Truly seasonal diseases: they occur every year practically at the same time and are closely related to changes in time as a consequence of the astronomical stations; 2) Pseudo-seasonal processes: transmissible and non-communicable diseases that have their maximum development at certain periods of the year (e.g. summer or winter) but not necessarily in the same month of each year nor coinciding with the astronomical stations; 3) Indirect seasonal effects: processes that are indirectly affected by several factors that change during different seasons, such as changes in the class and composition of food, dress, daily amount of physical exercise, facilities and modalities of human contact, in species and density of insect vectors, etc. [5].

Seasonal variations are those that occur regularly at certain times of the year. The study of this phenomenon has enough interest to know the environmental or personal factors that influence, or the variation in exposure to infectious agents due to the natural life cycle of the infectious agent, or changes in the opportunity for exposure, or variations in habits, such as diet, or variations in exposure to allergens or other environmental factors, or the possible Influence of sunlight, cold or heat, humidity, barometric pressure, exercise or physical inactivity in winter versus summer, environmental pollution, the winter rains and the high temperatures that advance spring allergies To pollen, etc. All of these are factors that are likely to be able to act on seasonal variations of diseases, as well as on morbidity which is attended in general practice and health care system, and it forces to adapting the services to the variability of demand.

Although the environment has a clear influence on health, the seasonal variation of diseases is a topic under discussion, although for various pathologies it seems to have been demonstrated. There are diseases and/or health problems or health events where studies of possible seasonal variation have been more comprehensive. Diseases such as psychiatric disorders (depression, mania, schizophrenia, suicide), ulcerative colitis, respiratory diseases, infectious diseases, allergies, births, sudden infant death, heart disease, etc., have been studied (Table 1) [6-34].

\begin{tabular}{|c|c|}
\hline Seasonal Variation & Disease \\
\hline Heat wave & $\begin{array}{l}\text { Increased risk of death in elderly people with diseases that are socially isolated and without access to } \\
\text { air conditioning }[6,7]\end{array}$ \\
\hline Acute bronchitis & A peak in January [8] \\
\hline $\begin{array}{l}\text { Cholesterol in patients with acute coronary syndrome under } \\
\text { treatment with statins }\end{array}$ & Greater amounts of lipids in winter vs. summer [9] \\
\hline Alcohol intoxication and drinking & Intoxication-related deaths peak during weekend and around festival days [10] \\
\hline Coronary heart disease and stroke & $\begin{array}{l}\text { New cases of coronary heart disease have maximum numbers in winter (January) and on Mondays } \\
\text { and Fridays }[11,12] \\
\text { Plasma fibrinogen concentrations showed the greatest seasonal change and were } 23 \% \text { higher in the } \\
\text { coldest six months compared with summer months [13] }\end{array}$ \\
\hline Depression and Attempted Suicide & $\begin{array}{l}\text { A peak of depression in the late spring and autumn [14] } \\
\text { Suicide attempt: higher prevalence in spring-summer [15-17] }\end{array}$ \\
\hline Weight (without medical intervention) & The maximum figures in winter \\
\hline Allergies & Spring (mainly grasses) $[18,19]$ \\
\hline Tuberculosis & Peak of new cases in summer [20] \\
\hline $\begin{array}{l}\text { Infectious diseases of the upper respiratory tract (acute } \\
\text { bronchitis, tonsillitis, otitis, oral infections, syncytial virus, } \\
\text { influenza ...) }\end{array}$ & $\begin{array}{l}\text { Peaks of incidence in the cold and humid months }[21,22] \\
\text { Unspecified viral }(1-30 / \% \text { of all diagnoses) and otitis media }(1-40 \%) \text {, could be seen as closely related } \\
\text { to respiratory tract infections and showed similar seasonal patterns [23] }\end{array}$ \\
\hline Hypertension & $\begin{array}{l}\text { Ambulatory blood pressures are higher in the winter [24] } \\
\text { For each age, sex, and treatment group systolic and diastolic pressures were higher in winter than in } \\
\text { summer. } \\
\text { The seasonal variation in blood pressure was greater in older than in younger subject [25] }\end{array}$ \\
\hline
\end{tabular}




\begin{tabular}{|c|c|}
\hline Uric acid & The level is higher in summer [26] \\
\hline Hyperthyroidism & Higher incidence in summer [27] \\
\hline Hip fracture & High rates in the winter [28] \\
\hline Acute Appendicitis & The maximum rates occur in summer [29] \\
\hline AIDS & $\begin{array}{l}\text { Epidemic acceleration in some areas of the Central Africa in the first } 8 \text { months of each year (the } \\
\text { seasonal patterns of nutritional deficiency which occur under some tropical agricultural systems) [30] }\end{array}$ \\
\hline Cutaneous malignant melanoma & The peaks in incidence occurred in the summer [31] \\
\hline Osteoarthritis & $\begin{array}{l}\text { Precipitation affected degree of pain for urban subjects who identified weather as a pain-generating } \\
\text { factor; barometric pressure, relative humidity and sunshine were significant factors influencing pain- } \\
\text { related stress [32] } \\
\text { Spring peak for consultations [33] }\end{array}$ \\
\hline Type I (insulin-dependent) diabetes mellitus & $\begin{array}{l}\text { There was slight seasonality, with a } 28 \% \text { higher rate of onset in fall and winter than in spring and } \\
\text { summer [34] }\end{array}$ \\
\hline
\end{tabular}

Table 1: Some common diseases and their seasonal variation described.

\section{Some diseases appear to occur with a pattern of seasonal variation}

Psychiatric disorders are more frequent in winter, but there are more suicides in the spring; Increases weight in winter, and decreases in summer; Tuberculosis seems to predominate in summer; Coronary disease presents two peaks in spring and autumn, but for others mortality is higher in winter; We also describe more winter mortality of stroke, and thromboembolism; Blood pressure is higher in winter than in summer; Allergies occur in stations with environmental pollen; Respiratory diseases have higher winter mortality due to pneumonias and bronchitis, and also more cases of respiratory viral infections in winter; The concentration of cholesterol in blood rises in winter and low in summer; Serum uric acid is higher in summer; There is a higher rate of onset of diabetes in autumn and winter; Deaths from alcohol poisoning are more frequent on weekends and around holiday dates; Infectious diseases are more frequent in winter, such as influenza, but appendicitis is more frequent in summer; Diarrhoea is also more frequent in summer; Digestive problems predominate in winter and spring; More are consulted for arthrosis in the spring; Hip fractures are more frequent in winter; The highest frequency of traffic accidents is during spring and summer holidays; In summer: are mare frequent those infectious diseases transmitted by mosquitoes: dengue, malaria, etc., and when they are the contaminated warm waters: cholera, hepatitis A. Also, there are diseases which depend of the very heat as the dehydration. The rains and floods, allow the formation of puddles and with it the proliferation of mosquitoes transmitters of diseases like the classic dengue and the haemorrhagic and the malaria. Moisture and cold causes skin conditions, causing fungal infections, allergy dermatitis or dryness. Moisture also increases mucosal infections, so that conjunctivitis is another disease that occurs most frequently in the summer and fall (Table 1).

The spring and autumn months have a higher frequency of almost all diseases ... and especially in the autumn months, where the highest frequencies are reached. Despite this, the seasonal variation of diseases is currently a topic under discussion and further study is needed. The reasons for the seasonal variation of certain diseases such as gastritis, falls/injuries, and toothache need to be explored further. Similarly, for example, the cause of the increase in fibrinogen in spring is unknown, or why in the winter months the number of deep venous thrombosis increases.

The influence of the seasonal variation of the diseases on the morbidity attended in family medicine continues being an unattended phenomenon which it is necessary to continue studying

The seasonal variation of diseases in family medicine is a phenomenon whose knowledge is essential for the improvement of health care and for improving the knowledge of the aetiology of health and its problems. It has long been accepted that morbidity patterns in general practice vary seasonally. As expected, seasonal fluctuations in morbidity were most apparent in respiratory disorders, though a small number of non-respiratory problems showed similar variations (unspecified viral (1\%-30\% of all diagnoses) and otitis media $(1 \%-40 \%)$, could be seen as closely related to respiratory tract infections and showed similar seasonal patterns) [23].

In general, the type of existing studies on the seasonal variation of diseases/health problems in general practice focus on a particular pathology [23]. This is due to the difficulty of the morbidity registers, in terms of their correct definition and registration of the problem, as well as the large number of data to be handled, it's difficult interpretation and the inherent biases. Several authors have shown the seasonal variation of diseases in family medicine, but it is not clear whether this seasonal variation of health problems leads to a seasonal variation in the morbidity seen in family medicine, and reasons may be the difficulty of diagnosis (the presence of self-limiting diseases, specificity and sensitivity-the more specific a diagnosis is, less reliable it is), variations in practice among professionals, and adequate record keeping, and the morbidity is influenced not only by the presence of physical and/or psychological symptoms, but also by other nonmedical factors (socio-demographic). On the other hand, medical care may also be influenced by a seasonal variation in referrals, complementary tests, and drug use.

In any case, it can be admitted that the acute and chronic morbidity seen in family medicine, when studied on a geographic basis and during the whole natural year, for a high number of reasons for 
consultation, follows a pattern of cyclical variation and/or seasonal there being a clear predominance of acute pathology of infectious origin especially during the months of September-November and March-May, in our context (Spain) and highlighting in females, except for the first stage of life. At the same time, the complementary explorations resulting from these consultations have also been presented with seasonal differences. Therefore, the planning and development of primary health care programs should take into account this circumstance in order to improve care for the population by reordering the distribution of means [35]. The usefulness of the knowledge of the seasonal variations of the diseases lies in the possibility of generating causal hypotheses and of risk and preventive factors, geographical comparisons, predicting the demand and distributing resources in a community, and facilitating the bio psychosocial or holistic approach [36].

\section{Some implications in the family medicine of seasonal variations of diseases}

- Aid for diagnosis

- Adequate interpretation - avoiding temporal bias - of prevalence or incidence studies

- For the prevention and implementation of health care strategies (for example, for advising that patients should avoid intense activity at certain times of the day, especially in the winter)

- Awareness of risks

- Surveillance systems

- Trial in pandemic situations (for example, with face-to-face and telephone triage systems to detect suspicious cases, assess the severity of the case, identify the risk of complications and finally guide the patient towards self-care home treatment, attendance at a Health Center for assessment or consultation in a hospital emergency department)

- Vaccination

- Generate causal and risk factor hypotheses

- Geographical comparisons,

- Foresee the demand and distribute resources in a community

- Facilitate the bio psychosocial approach or holistic and familiar (for example, respiratory diseases that affect all the members of the family group, being more worrisome the case of the small children, old adults and people with chronic pathologies)

\section{Seasonal variation of infectious diseases}

Seasonal change in the incidence of infectious diseases is a common phenomenon in both temperate and tropical climates. However, the mechanisms responsible for seasonal disease incidence, and the epidemiological consequences of seasonality, are poorly understood with rare exception. Due of seasonality can be derived several new results concerning vaccination strategies and the interpretation of disease outbreaks data [37]. Basically, the dynamics of an infectious disease can be endemic, seasonal, epidemic or cyclic, but may present irregular variations superimposed on these patterns, and in some cases be chaotic, which hinders or prevents their long-term prediction. The dynamics of measles, mumps and rubella in Denmark (1928-68) are chaotic. The same has been noted for measles in New York and Baltimore (1928-63) and for meningococcal meningitis in Chile (1975-95) [38].
Infectious processes represent a significant volume of visits to a health centre. Thus, acute upper respiratory infection and acute bronchitis constitute $15 \%$ of the total visits in the primary care consultation, and $50 \%$ of urgent consultations of Primary Care Centres corresponded to respiratory diseases. Although the seasonal variations of some infectious processes can be intuited in daily practice- the clinical experience seems to show that the infectious processes in primary care constitute a disease that undergoes periodic changes (epidemics) and that affects large groups of the population attended at certain times of the year (for example, gastroenteritis in summer season or catarrhal symptoms In autumn and spring)-, few studies have been done on this phenomenon in the demanding population served in the primary care area. In any case, it can be affirmed that respiratory problems represent the most important percentage of infections; so the seasonal variability of infections, in general practice, can be attributed to the variability of respiratory infections [39].

Respiratory infections are a threat and constitute a major public health problem because they are a major cause of morbidity and mortality worldwide. The most important predisposing factors are environmental and social. Environmental factors include environmental pollution inside or outside the home, smoking, poor ventilation of the home, sudden changes in temperature, attendance to places with high concentrations of people, and contact with sick people. In annual influenza epidemics, clinical attack rates can range from $5 \%$ to $20 \%$ in the general community and up to $50 \%$ in closed population groups. These annual seasonal influenza epidemics impose a significant health burden on all age groups, although the highest risk of complications is for children under the age of two, for adults over the age of 64, for pregnant women and for persons of any age with certain medical conditions such as cardiovascular, pulmonary, renal, hepatic, hematic, chronic or metabolic disorders (such as diabetes), immunosuppression and neural or neuromuscular disorders that may affect respiratory function or elimination of respiratory secretions. Among the secondary complications of influenza are bacterial pneumonia, including concomitant infection with methicillin-resistant Staphylococcus aureus and Streptococcus pneumoniae, viral pneumonia, worsening of underlying conditions, sinusitis, otitis media, etc.

In temperate climates, flu infections at whatever level of intensity are characterized by a "flu season". In these areas, the disease is thought to exist at a low level throughout the year but exhibit a marked seasonal increase, typically during the winter months. Influenza epidemics and outbreaks occur in tropical areas as well, although the timing and impact are not as well defined. Local epidemics begin suddenly, with a peak in 2 to 3 weeks, and last for a total of 5 to 10 weeks. It is believed that in most cases seasonal outbreaks of influenza originate in China and spread from there. Infectious disease dynamics offer a wide variety of intriguing and unexplained phenomena, yet none is as consistently observed while still remaining so poorly understood as the seasonality of influenza. There is a gap in how diverse studies encompassing immunology, mathematics, epidemiology, and virology combine to form a complete picture of flu seasonality. This may be due to the daunting complexity of seasonality itself, which is likely to reflect the actions of a vast multitude of variables. For whatever reason, only limited research has actually focused on supporting or rejecting each of the proposed underlying causes of the seasonality of influenza, and most of these, while thorough and well supported, are largely confined to a single discipline. 
The cyclical patterns of other viral diseases with different immunological and virological behaviours can provide useful comparisons to those of influenza virus. Measles shows a clear cyclical epidemic pattern, although outbreaks are often separated by years rather than seasons. However, in this disease, human immune memory provides a powerful, lifelong immunity subsequent to initial exposure. Theoretical modelling of viral evolution, or empirical studies, when combined with the examination of high-level weather events, mass population mixing, and other seasonality factors could establish whether viral evolution is a cause or an effect of differing pathogenhost relations and disease profiles and how these interact on a microbiological level, where vaccines and prophylactics can address the disease directly.

On the other hand, there may be also a seasonal host health. Seasonal variations in the health and physiological statuses of animals are quite common. It is not surprising that the immune system may experience a pattern of ebb and flow that could leave a host animal vulnerable to infection. It has been suggested that the observed seasonality of influenza is the result not of sweeping waves of disease traveling across the globe but rather of a constant level of infection mediated differently by the host immune system over time. Specifically, it has been posited that light/dark cycles, manifesting as melatonin levels, may have an impact on the immune system, rendering the host more susceptible to infection at different times of the year by pathogens which are present year-round. Two possible intermediaries between photoperiod and immunity are melatonin and vitamin $\mathrm{D}$ (25-hydroxy-vitamin $\mathrm{D})$. The relative impact of each as well as other factors is not yet quantified, however, and there is ample opportunity for further examination. Has been communicated that subjects exposed to influenza virus during the summer were less likely to develop the disease than those exposed in the winter, which suggesting a host-based defence mechanism active at high levels during the summer. They have not been explored the possibility of seasonal fluctuations in the nature of the virus itself. A clear and definitive relationship between photoperiod, host immune response, and influenza virus infection has yet to emerge, but the groundwork has been laid for continuing research. Host nutrient intake may also contribute to the seasonal patterns of flu occurrence. As both vitamins are taken up in food, it has been proposed that seasonal fluctuations in diet (due to the availability of certain foods) lead to a decrease in antioxidant levels, an increase in oxidative stress, and a commensurate increase in viral mutation and, therefore, infection rates [40].

\section{Conclusion}

Many diseases have a seasonal variation. There are diseases and health problems or health events where studies of possible seasonal variation have been more comprehensive. Diseases such as psychiatric disorders (depression, mania, schizophrenia, and suicide), ulcerative colitis, respiratory diseases, infectious diseases, allergies, births, sudden infant death, heart disease, etc., have been studied. In general medicine, a high number of reasons for consultation follow a pattern of cyclical and seasonal variation, with a clear predominance of acute pathology of infectious origin, And within them predominate respiratory infections.

Infectious disease dynamics offer a wide variety of intriguing and unexplained phenomena, yet none is as consistently observed while still remaining so poorly understood as the seasonality of influenza. There is a gap in how diverse studies encompassing immunology, mathematics, epidemiology, and virology combine to form a complete picture of seasonality. This may be due to the daunting complexity of seasonality itself, which is likely to reflect the actions of a vast multitude of variables. The reasons for the seasonal variation of certain diseases need to be explored further. Studies seeking novel mechanisms and those providing both biological plausibility and epidemiological evidence for existing theories are needed. An understanding of what drives seasonal trends may allow better understanding of transmission dynamics, leading to better methods of prevention of annual endemic outbreaks. And general medicine, by its characteristics, has a fundamental role in those epidemiological studies [41-43].

The burden of these diseases could be reduced if we take measures to detect the changes in their trend through the implementation of surveillance programs. Control of the infectious diseases may entail measures for enhancing the socioeconomic development along with specific health measures for a sustained effect. Among the implications of the knowledge of seasonal variations of diseases in family medicine are: 1) Adequate interpretation of prevalence or incidence studies; 2) Aid for diagnosis; 3) Preventive and educational interventions; 4) Redistribution of resources for the attention of the demand and triage; 5) Awareness of risks and Surveillance systems; 6) generate causal and risk factor hypotheses; and 7) vaccinations.

\section{References}

1. Turabián JL, Gutiérrez V (1996) Variations in frequencies of chronic illnesses and risk factors in Primary Care (1985-1995). Aten Primaria 18: 65-69.

2. Knottnerus JA (1992) Annual and seasonal variation in the incidence of common diseases. Br J Gen Pract 42: 86.

3. Fleming DM, Norbury CA, Crombie DL (1991) Annual and seasonal variation in the incidence of common diseases. Occas Pap R Coll Gen Pract: 1-24.

4. Pascual M, Dobson A (2005) Seasonal patterns of infectious diseases. PLoS Med 2: e5.

5. Martín SGJ, de Rivera GJL, González GJ (1988) Seasonality and psychopathology. Psiquis IX: 92-101.

6. Semenza JC, Rubin CH, Falter KH, Selanikio JD, Flanders WD, et al (1996) Heat-related deaths during the July 1995 heat wave in Chicago. N Engl J Med 335: 84-90.

7. Díez BF (1996) Meteorology and health. The relationship between environmental temperature and mortality. Rev Esp Public Health 70: 251-259.

8. Ayres JG (1986) Seasonal pattern of acute bronchitis in general practice in the United Kingdom 1976-83. Thorax 41:106-10.

9. Tung P, Wiviott SD, Cannon CP, Murphy SA, McCabe CH, et al. (2009) Seasonal variation in lipids in patients following acute coronary syndrome on fixed doses of Pravastatin $(40 \mathrm{mg}$ ) or Atorvastatin $(80 \mathrm{mg}$ ) (from the Pravastatin or Atorvastatin Evaluation and Infection TherapyThrombolysis In Myocardial Infarction 22 [PROVE IT-TIMI 22] Study). Am J Cardiol 103: 1056-1060.

10. Makela P, Martikainen P, Nihtila E (2005) Temporal variation in deaths related to alcohol intoxication and drinking. Int J Epidemiol 34: 765-771.

11. Meal AG, Pringle M, Hammersley V (2000) Time changes in new cases of ischaemic heart disease in general practice. Fam Pract 17: 394-400.

12. Douglas AS, Dunnigan MG, Allan TM, Rawles JM (1995) Seasonal variation in coronary heart disease in Scotland. J Epidemiol Community Health 49: 575-82.

13. Stout RW, Crawford V (1991) Seasonal variations in fibrinogen concentrations among elderly people. Lancet 338: 9-13.

14. Harris CM (1986) Further observations of seasonal variation. 2. Depression. J R Coll Gen Pract 36: 319-321. 
Citation: Turabian JL (2017) The Variation of Seasonal Diseases in Family Medicine Depends on Infectious Diseases and these are Mainly Respiratory Diseases. J Gen Pract (Los Angel) 5: 309. doi:10.4172/2329-9126.1000309

Page 6 of 6

15. González GMJ, García AC, López PA (1997) The influence of bioclimatology on suicides. Aten Primaria19: 177-182.

16. Eastwood MR, Peacocke J (1976) Seasonal patterns of suicide, depression and electroconvulsive therapy. Br J Psychiat 129: 472-475.

17. González GMJ (1998) Influence of meteorology on psychiatric emergencies and suicides. Semergen 5: 357-366.

18. Labaca GI, Navarrete CI (1992) Origin and distribution of seasonal allergy. A vision from primary care. Aten Primaria 10: 1019-1023.

19. Sibbald B, Rink E (1991) Epidemiology of seasonal and perennial rhinitis: Clinical presentation and medical history. Thorax 46: 895-901.

20. Leung CC, Yew WW, Chan TYK, Tam CM, Chan CY, et al. ((2005) Seasonal pattern of tuberculosis in Hong Kong. Int J Epidemiol 34: 924-930.

21. Viegas M, Barrero PR, Maffey AF, Mistchenko AS (2004) Respiratory viruses seasonality in children under five years of age in Buenos Aires, Argentina: A five-year analysis. J Infect 49: 222-228.

22. González SB, Díaz SL, Rutllant WMP, Arbeloa MJM, Bargallo VE, et al. (1996) Infectious pathology in primary care. Aten Primaria 17: 64-69.

23. Hallam L, Metcalfe DH (1985) Seasonal variations in the process of care in urban general practice. J Epidemiol Community Health 39: 90-93.

24. Goodwin J, Pearce VR, Taylor RS, Read KL, Powers SJ (2001) Seasonal cold and circadian changes in blood pressure and physical activity in young and elderly people. Age Ageing 30: 311-317.

25. Brennan PJ, Greenberg G, Miall WE, Thompson SG (1982) Seasonal variation in arterial blood pressure. Br Med J (Clin Res Ed) 285: 919-923.

26. Revert MJ, Lahuerta MJJ, Porcar AL (2000) Seasonal variation in plasma concentrations in uric acid and its implications for the clinical profile. Aten Primaria 26: 468-471.

27. Westphal SA (1994) Seasonal variation in the diagnosis of Graves' disease. Clin Endocrinol (Oxf) 41: 27-30.

28. Jacobsen SJ, Goldberg J, Miles TP, Brody JA, Stiers W, et al. (1991) Seasonal variation in the incidence of hip fracture among white persons aged 65 years and older in the United States, 1984-1987. Am J Epidemiol 133: 996-1004.

29. Luckmann R, Davis P (1991) The epidemiology of acute appendicitis in California: Racial, gender, and seasonal variation. Epidemiology 2: 323-330.
30. Raynor SMR, Cliff AD (1992) Seasonality in tropical AIDS: A geographical analysis. Int J Epidemiol 21: 547-556.

31. Schwartz SM, Armstrong BK, Weiss NS (1987) Seasonal variation in the incidence of cutaneous malignant melanoma: an analysis by body site and histologic type. Am J Epidemiol 126: 104-111.

32. Laborde JM, Dando WA, Powers MJ (1986) Influence of weather on osteoarthritics. Soc Sci Med 23: 549-554.

33. Harris CM (1986) Further observations on seasonal variation. 1. Osteoarthritis. J R Coll Gen Pract 36: 316-318.

34. Siemiatycki J, Colle E, Aubert D, Campbell S, Belmonte MM (1986) The distribution of by age, sex, secular trend, seasonality, time clusters, and space-time clusters: Evidence from Montreal, 1971-1983. Am J Epidemiol 124: 545-560.

35. http://eprints.ucm.es/tesis/19911996/D/0/AD0019501.pdf

36. Ferrera VA, Lapeira TJM, Raya AMC, García PI, Rayo MS, et al. (2009) Five key questions on the flu: A guide review. Rev Clin Med Fam: 2.

37. Grassly NC, Fraser C (2006) Seasonal infectious disease epidemiology. Proc Biol Sci 273: 2541-2550.

38. Mauricio Canals L, Fabián Labra S (1999) Análisis no-lineal de la dinámica de enfermedades infecciosas en Chile. Rev Méd Chile: 127.

39. Lofgren E, Fefferman NH, Naumov YN, Gorski J, Naumova EN (2007) Influenza seasonality: Underlying causes and modeling theories. J Virol 81: 5429-5436

40. Kumari R, Nath B, Midha T, Vaswani ND, Lekhwani S, et al. (2012) Morbidity profile and seasonal variation of diseases in a primary health center in Kanpur district: A tool for the health planners. J Family Med Prim Care 1: 86-91.

41. Turabián JL, Ruiz MS, Jove CR (2016) "Doctor, I have Chikungunya". Conceptual systematisation of specific epidemiological implications in family medicine. Semergen 42: 488-491.

42. Turabian JL, Ruiz MS, Jove CR (2016) Epidemiology in Family Medicine. J Gen Pract (Los Angel) 4: 278.

43. Turabian JL, Montiel BB, Islas GE (2016) Implications of Incidence Rates of Diseases at Local Level in Family Medicine. Fam Med 1: 002. 